\title{
Modeling and Direct Power Control Method of Vienna Rectifiers Using the Sliding Mode Control Approach
}

\author{
Hui $\mathrm{Ma}^{\dagger}$, Yunxiang Xie*, Biaoguang Sun ${ }^{*}$, and Lingjun $\mathrm{Mo}^{*}$ \\ ${ }^{\dagger *}$ School of Electrical Power, South China University of Technology, Guangzhou, China
}

\begin{abstract}
This paper uses the switching function approach to present a simple state model of the Vienna-type rectifier. The approach introduces the relationship between the DC-link neutral point voltage and the AC side phase currents. A novel direct power control (DPC) strategy, which is based on the sliding mode control (SMC) for Vienna I rectifiers, is developed using the proposed power model in the stationary $\alpha-\beta$ reference frames. The SMC-based DPC methodology directly regulates instantaneous active and reactive powers without transforming to a synchronous rotating coordinate reference frame or a tracking phase angle of grid voltage. Moreover, the required rectifier control voltages are directly calculated by utilizing the non-linear SMC scheme. Theoretically, active and reactive power flows are controlled without ripple or cross coupling. Furthermore, the fixed-switching frequency is obtained by employing the simplified space vector modulation (SVM). SVM solves the complicated designing problem of the AC harmonic filter. The simplified SVM is based on the simplification of the space vector diagram of a three-level converter into that of a two-level converter. The dwelling time calculation and switching sequence selection are easily implemented like those in the conventional two-level rectifier. Replacing the current control loops with power control loops simplifies the system design and enhances the transient performance. The simulation models in MATLAB/Simulink and the digital signal processor-controlled $1.5 \mathrm{~kW}$ Vienna-type rectifier are used to verify the fast responses and robustness of the proposed control scheme.
\end{abstract}

Keywords: Direct power control (DPC), Power model, Sliding mode control (SMC), Vienna-type rectifier

\section{INTRODUCTION}

Vienna-type rectifiers have attracted wide attention in recent years because of their unidirectional power conversion ability that fulfills high power density requirements [1]-[4]. The Vienna-type rectifiers offer many other advantages over conventional three-level rectifiers. These advantages include requiring fewer active switching components in producing the same number of voltage levels, high input power factor, and low device voltage stress. This type of rectifier is also well known for its low control complexity and low sensing effort in terms of control system design and implementation [1], [2]. Therefore, the Vienna-type rectifier potentially reduces cost and provides more design flexibility for industry applications.

Extensive research has been conducted on rectifier control

Manuscript received May 15, 2014; accepted Aug. 16, 2014

Recommended for publication by Associate Editor Trillion Q Zheng.

†Corresponding Author: mahuizz119@126.com

Tel: +82-15112173870, South China University of Technology

*School of Electrical Power, South China University of Tech, China schemes in the past few years [5]-[12]. Furthermore, several control approaches have been presented for the Vienna-type rectifier. These approaches include the hysteresis current control method [8], constant-frequency integration control scheme [11], [12], conventional direct power control strategy, [4], [9] and unity power factor control method [6], [7]. These approaches have different disadvantages. The hysteresis current control has a varying switching frequency, which is its drawback. The unity power factor and the constant-frequency integration controls do not provide a closed-loop regulation for the neutral point voltage balance of the DC link capacitors. Meanwhile, proportional-integral (PI) controllers are sensitive to changes of the component's parameters and load. The PI controllers experience lag in the sinusoid response for certain frequencies [13]. The direct power based on the SVM control has to track the phase angle of the grid voltage and transform to a synchronous rotating coordinate reference frame [14], [15]. The sliding mode control methodology is an effective, high-frequency switching control for non-linear systems with uncertainties. 


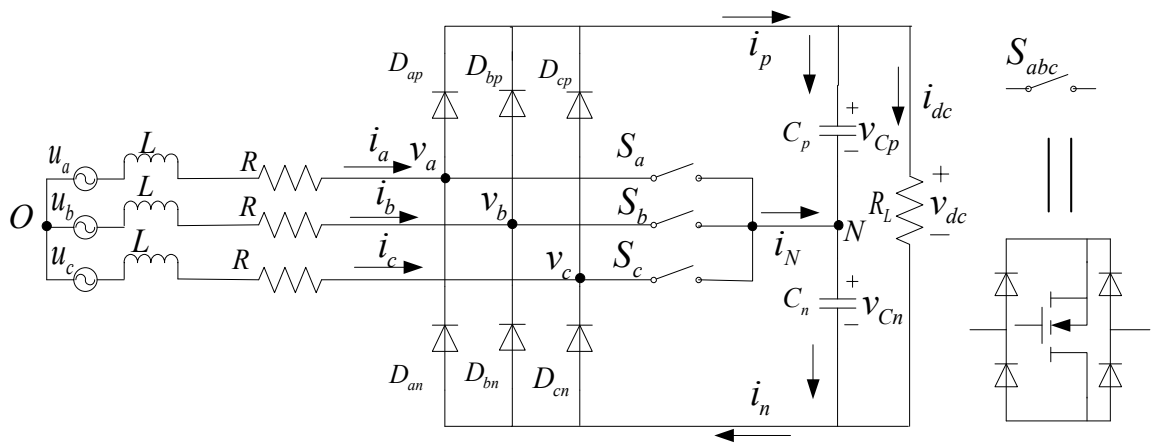

Fig. 1. Topology of the three-phase/level Vienna I rectifier method.

The method features simple implementation, disturbance rejection, strong robustness, and fast responses [13]. This paper proposes a sliding mode control (SMC)-direct power control (DPC) strategy to overcome the drawbacks of the existing methods in conventional direct power control and eliminate the drawback of a varying switching frequency using the simplified space vector modulation (SVM) schemes.

This paper is divided into six sections. Section I presents the introduction, gives the brief advantages of the Vienna-type topology, and discusses several control methods for the Vienna-type rectifiers. Section II introduces a high-frequency model suited for half-switching frequency. This model is based on the operation analysis and the relationship between the neutral point voltage and the $\mathrm{AC}$ currents. The relationship states that the neutral point voltage balance is effectively managed by regulating the time of a redundant small vector pair during a duty cycle. Section III describes the power model of the Vienna-type rectifier in the stationary $\alpha-\beta$ reference frame, which is used to analyze the direct power control schemes and design the sliding surface. The proposed control methodology is presented for the rectifier system based on Section III. The sliding mode control methodology is thoroughly demonstrated in Section IV. Relying on these two techniques, a sliding surface is defined in function of the instantaneous active and reactive powers, and the system is controlled to remain on the surface. Section V enlists the simplified SVM and the DC-link neutral-point voltage balance control method. Section VI demonstrates the simulation and experimental results. Section VII presents the conclusion.

\section{OPERATING MODE OF THE VIENNA-TYPE RECTIFIER}

The Vienna I rectifier topology is shown in Fig. 1. The rectifier comprises the main diode bridge and three bidirectional switching units. The three active switching units comprise diode rectifiers and active switches controlled to ensure sinusoidal AC current, steady DC voltage, and neutral point stabilization. From an operational view, the Vienna I rectifier is a three-level non-regenerate boost rectifier referring to figures of three-phase rectifiers. The mathematical model equations of the Vienna I rectifier are deduced using Eq. (1). Accordingly, $u_{a, b, c}\left(u_{a}, u_{b}\right.$, and $\left.u_{c}\right)$ are the source voltages at the input side; $v_{a N}, v_{b N}$, and $v_{c N}$ are the switch voltages; $v_{N O}$ is the neutral point voltage across the middle point of the output capacitances and the main neutral; and $L$ and $R$ are the input inductance and the resistance values of the synchronous inductance, respectively. Meanwhile, $i_{p}$ and $i_{n}$ at the output side are the results added by the currents that flow in the upper diode bridge and those that flow under the diode bridge, respectively.

$$
\left\{\begin{array}{l}
L \frac{d i_{a, b, c}}{d t}=u_{a, b, c}-R \cdot i_{a, b, c}-\left(v_{(\mathrm{a}, \mathrm{b}, \mathrm{c}) N}+v_{N O}\right) \\
C_{p} \frac{d v_{C p}}{d t}=i_{p}-\frac{v_{c p}+v_{c n}}{R_{L}} \\
C_{n} \frac{d v_{C n}}{d t}=i_{n}-\frac{v_{c p}+v_{c n}}{R_{L}}
\end{array}\right.
$$

The active switch unit for the input stage is forced commutated current. Hence, the switch voltages (i.e., $v_{a N}$, $v_{b N}$, and $v_{c N}$ ) are determined by both the identical switch state and the polarity of the AC phase current flowing the inductance. For example, the logic equation for phase $\mathrm{A}$ is given by Eq. (2) as follows:

$$
v_{a N}= \begin{cases}0, & \text { if } S_{a} \text { is turn on } \\ v_{c p}, & \text { if } S_{a} \text { is turn off and } i_{a}>0 \\ -v_{c n}, & \text { if } S_{a} \text { is turn off and } i_{a}<0\end{cases}
$$

Similarly, the logic equations of the other two phases are obtained to write for the three switch voltages in only one equation. The equation is derived as follows:

$$
v_{(\mathrm{a}, \mathrm{b}, \mathrm{c}) N}=S_{(\mathrm{a}, \mathrm{b}, \mathrm{c}) \mathrm{p}} \cdot v_{c p}-S_{(\mathrm{a}, \mathrm{b}, \mathrm{c}) \mathrm{n}} \cdot v_{c n}
$$

where $S_{(a, b, c) p}$ and $S_{(a, b, c) n}$ are defined by Eq. (4) as follows:

$$
\begin{cases}S_{(\mathrm{a}, \mathrm{b}, \mathrm{c}) o}=0, & \text { if } S_{a, b, c} \text { is turn on } \\ S_{(\mathrm{a}, \mathrm{b}, \mathrm{c}) p}=1, & \text { if } S_{a, b, c} \text { is turn off and } i_{a, b, c}>0 \\ S_{(\mathrm{a}, \mathrm{b}, \mathrm{c}) n}=1, & \text { if } S_{a, b, c} \text { is turn off and } i_{a, b, c}<0\end{cases}
$$


Assuming that the utility grid is a symmetrical balanced three-phase system without any disturbance, using Eqs. (3) and (4) in Eq. (1) obtains the following equation:

$$
\begin{aligned}
v_{N O}= & -\frac{v_{a N}+v_{b N}+v_{c N}}{3} \\
= & -\frac{\sum_{k=a, b, c} S_{k p}}{3} v_{c p}+\frac{\sum_{k=a, b, c} S_{k n}}{3} v_{c n}
\end{aligned}
$$

According to Kirchhoff's law, $i_{p}$ and $i_{n}$ for the output stage are given by Eq. (6) using Eq. (4) as follows:

$$
\left\{\begin{array}{l}
i_{p}=S_{a p} \cdot i_{a}+S_{b p} \cdot i_{b}+S_{c p} \cdot i_{c} \\
i_{n}=-S_{a n} \cdot i_{a}-S_{b n} \cdot i_{b}-S_{c n} \cdot i_{c}
\end{array}\right.
$$

The other system variables are described by straightforward equations concluding these switching variables with switching functions (i.e., $S_{(a, b, c) p}, S_{(a, b, c) s}$, and $\left.S_{(a, b, c) n}\right)$. The state-space equation is neither constant nor continuous because $S_{(a, b, c) p}, S_{(a, b, c) o}$, and $S_{(a, b, c) n}$ are functions that describe the precise dynamics of the switching state. Substituting Eqs. (3), (4), and (6) of the system dynamics into Eq. (1) obtains

$$
Z \frac{d X}{d t}=A \cdot X+B \cdot U
$$

where

$$
\begin{aligned}
& Z=\operatorname{diag}\left[\begin{array}{lllll}
L & L & L & C_{p} & C_{n}
\end{array}\right]^{T} \\
& X=\left[\begin{array}{lllll}
i_{a} & i_{b} & i_{c} & v_{c p} & v_{c n}
\end{array}\right]^{T} \quad B=\operatorname{diag}\left[\begin{array}{lllll}
1 & 1 & 1 & 0 & 0
\end{array}\right] \\
& U=\left[\begin{array}{lllll}
u_{a} & u_{b} & u_{c} & 0 & 0
\end{array}\right]^{T} \\
& A=\left[\begin{array}{ccccc}
-R & 0 & 0 & -\left(S_{a p}-\frac{\sum_{k=a, b, c} S_{k p}}{3}\right) & \left(S_{a n}-\frac{\sum_{k=a, b, c} S_{k n}}{3}\right) \\
0 & -R & 0 & -\left(S_{b p}-\frac{\sum_{k=a, b, c} S_{k p}}{3}\right) & \left(S_{b n}-\frac{\sum_{k=a, b, c} S_{k n}}{3}\right) \\
0 & 0 & -R & -\left(S_{c p}-\frac{\sum_{k=a, b, c} S_{k p}}{3}\right) & \left(S_{c n}-\frac{\sum_{k=a, b, c} S_{k n}}{3}\right) \\
S_{a p} & S_{b p} & S_{c p} & -\frac{1}{R_{L}} & -\frac{1}{R_{L}} \\
-S_{a n} & -S_{b n} & -S_{c n} & -\frac{1}{R_{L}} & -\frac{1}{R_{L}}
\end{array}\right]
\end{aligned}
$$

Assuming the voltage balance of capacitors $C_{P}$ and $C_{n}$, these 25 valid switch combination states are subset of the 27 states because the Vienna rectifier is a three-level topology with only one zero state. The 25 voltage vectors are produced by the 25 possible switching state combinations. Accordingly, the 25 voltage vectors after Clark transformation to the stationary $\alpha-\beta$ reference system is divided into one zero vector, 12 small vectors composed by six redundant pairs, six medium, and six large vectors. The space vector representation of the 25 electrical states is presented in Fig. 2. A detailed description of the electrical states was also discussed in Refs. [16]-[18]. Theoretically, the two capacitors in the output side are assumed to have an equal capacity, and the grid is balance. The dynamics of the voltage balance $v_{c p}-v_{c n}$ is derived from Eqs. (4), (6), and (7) as follows:

$$
\begin{aligned}
& C \frac{d\left(v_{c p}-v_{c n}\right)}{d t}=\left(S_{a}-S_{c}\right) \cdot i_{a}+\left(S_{b}-S_{c}\right) \cdot i_{b} \\
& S_{a, b, c}=S_{(a, b, c) p}-S_{(a, b, c) n} \\
& S_{a, b, c} \in\{-1,0,1\}
\end{aligned}
$$

Table I presents the currents that flow into the neutral point of the DC-bus capacitor bank and the $v_{N O}$ values. The currents are differently supplied by the capacitors when the voltage levels are different at the capacitor terminals. The medium vectors are the major source of the capacitor voltage ripple found by observing the table that the zero vector and large vectors do not influence the neutral that the values of currents flowing into the neutral point are zeros [19]. Each pair of small vectors is also associated with two different switching states, which are referred to as positive and negative small vectors in Ref. [17]. Furthermore, the directions of the currents that flow into the neutral point have a direct relation to a particularly small vector. The charging and discharging times of each capacitor at the unity power factor, which are needed for rectification operations, are different. The charging and discharging profiles are repeated in every half cycle. This process produces unbalanced capacitor voltages between different levels. This type of capacitor unbalance voltage problem is resolved using different control strategies [20]-[22]. In this paper, regulating the time of a redundant small vector pair ensures that the neutral point voltage balance could be managed effectively [21], [22].

\section{StANDARD Direct POWER CONTROL MOdel}

The active and the reactive powers can be used to express three forms based on instantaneous reactive power theory. These three forms are the expressions described in the natural abc coordinate system, stationary reference frame, and rotating coordinate system. The values of the expressions are equal, and DC forms although the expressions differ in appearance. The active and the reactive power in this paper are described in the stationary reference frame. Hence, analyzing the circuit performances is convenient because the coupling of the active and the reactive powers is eliminated. Notably, the important difference between the Vienna and the traditional three-level rectifiers in the power transmission is that the power is transferred only from the AC to the DC side in the former.

The equivalent circuit of the Vienna I rectifier in the stationary $\alpha-\beta$ reference frame is shown in Fig. 3. According to Fig. 3, the mathematic model is expressed as follows: 
TABLE I

Neutral Point CurRents and $v_{N O}$ Values with ResPeCt to THE SWITCHING State VALUES

\begin{tabular}{|c|c|c|c|c|c|}
\hline \multirow{2}{*}{ Vector } & \multicolumn{3}{|c|}{ Conditions } & \multirow{2}{*}{$C \cdot \frac{d \Delta v}{d t}$} & \multirow{2}{*}{$v_{N O}\left(V_{d c}\right)$} \\
\cline { 2 - 4 } & $S_{a}$ & $S_{b}$ & $S_{c}$ & 0 & 0 \\
\hline$v_{0}$ & 0 & 0 & 0 & 0 & $-1 / 6$ \\
\hline$v_{1}$ & 1 & - & -1 & 0 & $1 / 6$ \\
\hline$v_{01+}$ & 1 & 0 & 0 & $-i_{a}$ & $-1 / 3$ \\
\hline$v_{01-}$ & 0 & -1 & -1 & $i_{a}$ & 0 \\
\hline$v_{12}$ & 1 & 0 & -1 & $i_{b}$ & 0 \\
\hline$v_{2}$ & 1 & 1 & -1 & 0 & $1 / 6$ \\
\hline$v_{02+}$ & 1 & 1 & 0 & $-i_{a}-i_{b}$ & $1 / 3$ \\
\hline$v_{02-}$ & 0 & 0 & -1 & $i_{a}+i_{b}$ & $-1 / 6$ \\
\hline$v_{23}$ & 0 & 1 & -1 & $i_{a}$ & 0 \\
\hline$v_{3}$ & -1 & 1 & -1 & 0 & $-1 / 6$ \\
\hline$v_{03+}$ & 0 & 1 & 0 & $-i_{b}$ & $1 / 6$ \\
\hline$v_{03-}$ & -1 & 0 & -1 & $i_{b}$ & $-1 / 3$ \\
\hline$v_{34}$ & -1 & 1 & 0 & $-i_{a}-i_{b}$ & 0 \\
\hline$v_{4}$ & -1 & 1 & 1 & 0 & $1 / 6$ \\
\hline$v_{04+}$ & 0 & 1 & 1 & $i_{a}$ & $1 / 3$ \\
\hline$v_{04-}$ & -1 & 0 & 0 & $-i_{a}$ & $-1 / 6$ \\
\hline$v_{45}$ & -1 & 0 & 1 & $i_{b}$ & 0 \\
\hline$v_{5}$ & -1 & -1 & 1 & 0 & $-1 / 6$ \\
\hline$v_{05+}$ & 0 & 0 & 1 & $i_{a}+i_{b}$ & $1 / 6$ \\
\hline$v_{05-}$ & -1 & -1 & 0 & $-i_{a}-i_{b}$ & $-1 / 3$ \\
\hline$v_{56}$ & 0 & -1 & 1 & $i_{a}$ & 0 \\
\hline$v_{6}$ & 1 & -1 & 1 & 0 & $1 / 6$ \\
\hline$v_{06+}$ & 1 & 0 & 1 & $i_{b}$ & $1 / 3$ \\
\hline$v_{06-}$ & 0 & -1 & 0 & $-i_{b}$ & $-1 / 6$ \\
\hline$v_{61}$ & 1 & -1 & 0 & $-i_{a}-i_{b}$ & 0 \\
\hline & & & & \\
\hline & & & 0 \\
\hline
\end{tabular}

$$
U_{\alpha \beta}=R \cdot I_{\alpha \beta}+L \frac{d I_{\alpha \beta}}{d t}+V_{\alpha \beta}
$$

where $U_{\alpha \beta}$ and $I_{\alpha \beta}$ are the source voltages and the AC phase currents, respectively; $L$ and $R$ are the input inductance and resistance values of the synchronous inductance, respectively; and $P$ and $Q$ are the active and reactive powers of the input side, respectively.

The active and the reactive powers of the input side are expressed in the composite power method as follows:

$$
P+j Q=\frac{3}{2} U_{\alpha \beta} I_{\alpha \beta}
$$

where

$$
\left\{\begin{array}{l}
P=\frac{3}{2}\left(u_{\alpha} i_{\alpha}+u_{\beta} i_{\beta}\right) \\
Q=\frac{3}{2}\left(-u_{\alpha} i_{\beta}+u_{\beta} i_{\alpha}\right)
\end{array}\right.
$$

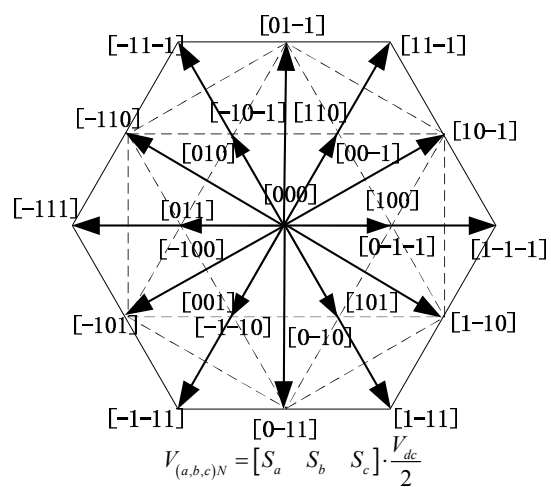

Fig. 2. Space vectors of the Vienna rectifier; $\left[S_{a} S_{b} S_{c}\right]$ takes values in $\{-1,0,1\}$.

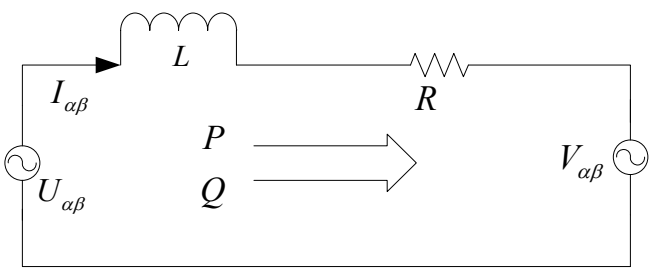

Fig. 3. Equivalent circuit of Vienna I rectifier in the stationary $\alpha-\beta$ reference frame.

The variations of the stator active and reactive powers are then obtained as follows:

$$
\left\{\begin{array}{l}
\frac{d P}{d t}=\frac{3}{2}\left(i_{\alpha} \frac{d u_{\alpha}}{d t}+i_{\beta} \frac{d u_{\beta}}{d t}+u_{\alpha} \frac{d i_{\alpha}}{d t}+u_{\beta} \frac{d i_{\beta}}{d t}\right) \\
\frac{d Q}{d t}=\frac{3}{2}\left(i_{\alpha} \frac{d u_{\beta}}{d t}-i_{\beta} \frac{d u_{\alpha}}{d t}+u_{\beta} \frac{d i_{\alpha}}{d t}-u_{\alpha} \frac{d i_{\beta}}{d t}\right)
\end{array}\right.
$$

The source voltage and the $\mathrm{AC}$ side current in the stationary reference frame during the network balance are obtained as follows when the utility grid is a symmetrical balanced three-phase system:

$$
\begin{gathered}
\left\{\begin{array}{c}
u_{\alpha}=\left|U_{\alpha \beta}\right| \cdot \sin (\omega t) \\
u_{\beta}=-\left|U_{\alpha \beta}\right| \cdot \cos (\omega t)
\end{array}\right. \\
\left\{\begin{array}{c}
i_{\alpha}=\left|I_{\alpha \beta}\right| \cdot \sin (\omega t+\theta) \\
i_{\beta}=-\left|I_{\alpha \beta}\right| \cdot \cos (\omega t+\theta)
\end{array}\right.
\end{gathered}
$$

where $\left|U_{\alpha \beta}\right|$ and $\left|I_{\alpha \beta}\right|$ are the amplitudes of the source voltage and the $\mathrm{AC}$ input current, respectively; and $\theta$ is the initial phase angle of the current. Based on Eq. (13), the variations of the source voltage are obtained as follows:

$$
\left\{\begin{array}{l}
\frac{d u_{\alpha}}{d t}=-\omega u_{\beta} \\
\frac{d u_{\beta}}{d t}=\omega u_{\alpha}
\end{array}\right.
$$

Subsequently, Eq. (15) is simplified as follows:

$$
\frac{d U_{\alpha \beta}}{d t}=j \omega U_{\alpha \beta}
$$

Based on Eqs. (9) and (14), the variations of the AC input current are obtained as follows: 


$$
\left\{\begin{array}{l}
\frac{d i_{\alpha}}{d t}=\frac{1}{L}\left(u_{\alpha}-R i_{\alpha}-v_{\alpha}\right) \\
\frac{d i_{\beta}}{d t}=\frac{1}{L}\left(u_{\beta}-R i_{\beta}-v_{\beta}\right)
\end{array}\right.
$$

Substituting Eqs. (11), (13), (15), and (17) into Eq. (12) to simplify the equation and eliminate the current components obtains the following equation:

$$
\left\{\begin{aligned}
\frac{d P}{d t}= & \frac{3}{2 L}\left[\left(u_{\alpha}^{2}+u_{\beta}^{2}\right)-\left(u_{\alpha} v_{\alpha}+u_{\beta} v_{\beta}\right)\right] \\
& +\frac{R}{L} P+\omega Q \\
\frac{d Q}{d t}= & \frac{3}{2 L}\left(-u_{\beta} v_{\alpha}+u_{\alpha} v_{\beta}\right)+\frac{R}{L} Q-\omega P
\end{aligned}\right.
$$

The proposed direct power control scheme indicates that Eq. (18) is the key factor for the slide mode control.

\section{PROPOSED SMC-DPC STRATEGY}

The outer loop is used to generate the current and power reference values when the inner loop is a current or a power loop control. Theoretically, the respective reference values of the reactive power loop and the reactive current loop are assigned as zeros to obtain unity power factor. The outer power loop is regulated by the PI controller that has been presented in detail in many papers [21], [23]. Hence, this paper does not discuss the outer power loop control method.

According to the principle of the conventional DPC for three-phase grid-connected rectifiers [15], [24], [25], an appropriate voltage vector is selected at each sampling instant through the certain switching rule to restrict instantaneous active and reactive power variations within their required hysteresis bands. The active and the reactive power controllers are two-level hysteresis comparators that generate discrete signals as inputs to the switching table based on the active and the reactive power errors [26]. The sector is located by the grid voltage vector. The switching signals of the Vienna I rectifier are directly generated according to a certain switching rule from a predefined lookup table [27]. Therefore, the original DPC algorithm is accomplished in the stationary reference frame without any pulse width modulation (PWM) module involved. The PWM module may achieve the maximum dynamic performance available [28]. However, the main disadvantage of this methodology is the varying switching frequency, which is not usually bounded and mainly depends on the sampling time, lookup table structure, load parameters, and operational state of the system. This methodology generates a dispersed harmonic spectrum that can hardly be used to design an effective line filter. Hence, the conventional lookup DPC strategy is not suitable for controlling the grid-connected Vienna rectifier. The problem of the varying switching frequency can be solved using the SVM. However, the direct power based on the

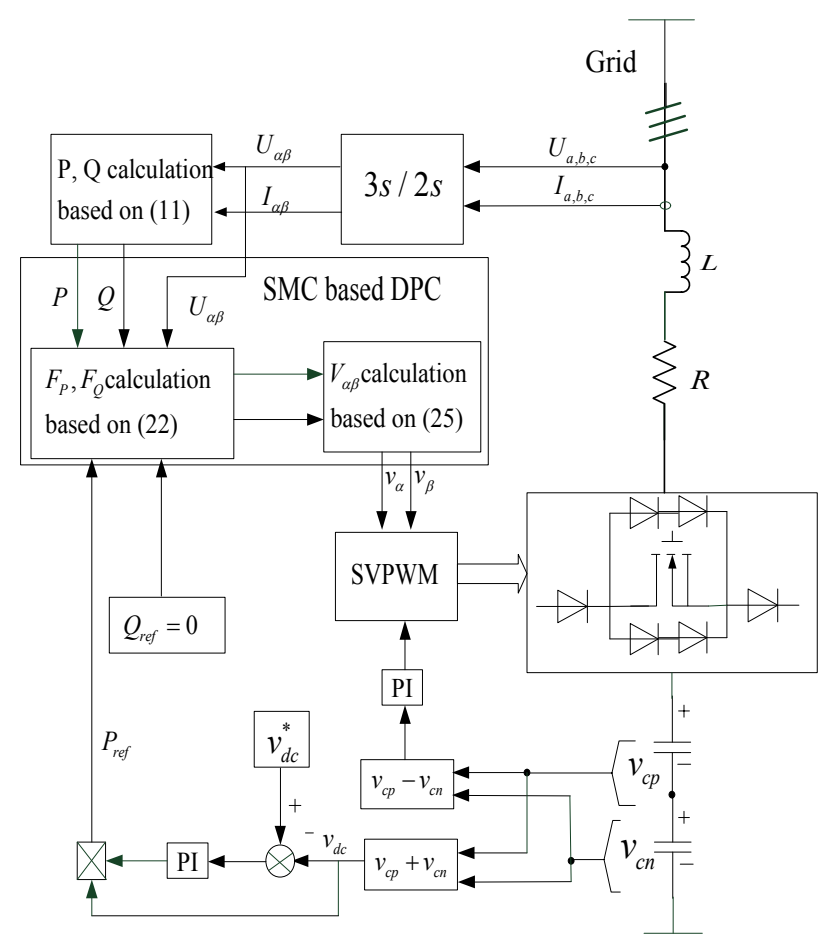

Fig. 4. Schematic diagram of the proposed SMC-based DPC for the Vienna I rectifier under the grid voltage balance.

SVM control has to track the phase angle of the grid voltage and transform to a synchronous rotating coordinate reference frame. Consequently, a new direct power control based on the SMC approach and the SVM scheme is proposed and designed for the grid-connected Vienna rectifier in the following section. The proposed SMC-DPC scheme is illustrated in Fig. 3, which illustrates the design of the control scheme with fixed switching frequency and high transient dynamics.

\section{A. Sliding Surface and Control Law}

The switching surfaces are designed as integral forms [29] to track the predefined trajectories of the active and the reactive powers accurately and maintain the minimization of the steady-state error and the enhanced transient response. The surfaces can also be designed using the back-stepping and non-linear damping techniques [30]. The sliding surface is set as follows:

$$
S=\left\{\begin{array}{l}
S_{1}=e_{P}(t)+K_{P} \int_{0}^{t} e_{P}(\tau) d \tau-e_{P}(0) \\
S_{2}=e_{Q}(t)+K_{Q} \int_{0}^{t} e_{Q}(\tau) d \tau-e_{Q}(0)
\end{array}\right.
$$

where $e_{P}(t)=P_{r e f}-P$ and $e_{Q}(t)=Q_{\text {ref }}-Q$ are the errors between the references and the calculated values of the instantaneous active and reactive powers, respectively; and $K_{P}$ and $K_{Q}$ are the positive control gains. The manifolds $S_{1}=0$ and $S_{2}=0$ represent the precise tracking of the active and the reactive powers of the Vienna I rectifier. Accordingly, $S_{1}=\dot{S}_{1}=0$ and $S_{2}=\dot{S}_{2}=0$ when the 
system states reach the sliding manifold and remain on the surface. Subsequently, Eq. (19) is obtained as follows when the derivatives of the sliding surface $S$ are equal to zero:

$$
\left\{\begin{array}{l}
\frac{d e_{P}(t)}{d t}=K_{P} e_{P}(t) \\
\frac{d e_{Q}(t)}{d t}=K_{Q} e_{Q}(t)
\end{array}\right.
$$

where $K_{P}$ and $K_{Q}$ are the positive control gains chosen to meet the requirements of the system. The preceding equation [Eq. (20)] ensures that the errors of the active and the reactive powers converge to zero. At the beginning, Eq. (19) is equal to zero. The system asymptotically converges to the origin with time constants of $1 / K_{P}$ and $1 / K_{Q}$, and the convergence rates of the error dynamics are determined by $K_{P}$ and $K_{Q}$.

The design task is then reduced to enforcing the sliding mode in the manifolds $S_{1}=0$ and $S_{2}=0$ using the discontinuous voltage space vectors of the Vienna I rectifier. The motion projections of the system [Eqs. (11) and (17)] on the $S$ subspace are derived by differentiating $S$ in Eq. (19) as follows:

$$
\left\{\begin{array}{l}
\dot{S}_{1}=\dot{e}_{P}(t)+K_{P} e_{P}(t)=\left(\dot{P}_{r e f}-\dot{P}\right)+K_{P}\left(P_{r e f}-P\right) \\
\dot{S}_{2}=\dot{e}_{Q}(t)+K_{Q} e_{Q}(t)=\left(\dot{Q}_{r e f}-\dot{Q}\right)+K_{Q}\left(Q_{r e f}-Q\right)
\end{array}\right.
$$

Substituting for $P, Q$, and their derivatives using Eq. (17) leads to the following equation:

$$
\dot{S}=F+D V_{\alpha \beta}
$$

where $F$ and $D$ are calculated as follows:

$$
\begin{aligned}
& F=\left[\begin{array}{c}
F_{P} \\
F_{Q}
\end{array}\right] \quad D=-\frac{3}{2 L}\left[\begin{array}{cc}
u_{\alpha} & u_{\beta} \\
u_{\beta} & -u_{\alpha}
\end{array}\right] \quad V_{\alpha \beta}=\left[\begin{array}{c}
v_{\alpha} \\
v_{\beta}
\end{array}\right] \\
& F_{P}=-\frac{3}{2 L}\left(u_{\alpha}^{2}+u_{\beta}^{2}\right)+\frac{R}{L} P+\omega Q+K_{P}\left(P_{r e f}-P\right) \\
& F_{Q}=\frac{R}{L} Q-\omega P+K_{Q}\left(Q_{r e f}-Q\right)
\end{aligned}
$$

A Lyapunov approach is usually used to derive the conditions in the SMC on the control law that drives the state orbit to the equilibrium manifold. The quadratic Lyapunov function is selected as follows:

$$
W=\frac{1}{2} S^{T} S \geq 0
$$

The time derivative of $W$ on the state trajectories of Eq. (22) is given as

$$
\dot{W}=\frac{1}{2}\left(S^{T} \dot{S}+S \dot{S}^{T}\right)=S^{T} \dot{S}=S^{T}\left(F+D V_{\alpha \beta}\right)
$$

The switching control law must be chosen so that the time derivative of $W$ is definitely negative with $S \neq 0$. Therefore, the control law is selected as follows:

$$
V_{\alpha \beta}=-D^{-1}\left\{\left[\begin{array}{l}
F_{P} \\
F_{Q}
\end{array}\right]+\left[\begin{array}{cc}
k_{1} & 0 \\
0 & k_{2}
\end{array}\right]\left[\begin{array}{l}
\operatorname{sign}\left(S_{1}\right) \\
\operatorname{sign}\left(S_{2}\right)
\end{array}\right]\right\}
$$

where $k_{1}$ and $k_{2}$ are the positive control gains, and $\operatorname{sign}\left(S_{1}\right)$ and $\operatorname{sign}\left(S_{2}\right)$ are the switching functions of the sliding surfaces.

\section{B. Proof of the Stability}

Having $\quad \dot{W}<0$ is sufficient for the stability of the switching surface. Assuming that the following condition is satisfied, stability is obtained by setting the positive control gains as follows:

$$
\begin{aligned}
& \text { If } S_{1} \operatorname{sign}\left(S_{1}\right)>0 \text { and } S_{2} \operatorname{sign}\left(S_{2}\right)>0 \text { then } \\
& \dot{W}=S^{T} \dot{S}=-S^{T}\left[\begin{array}{cc}
k_{1} & 0 \\
0 & k_{2}
\end{array}\right]\left[\begin{array}{l}
\operatorname{sign}\left(S_{1}\right) \\
\operatorname{sign}\left(S_{2}\right)
\end{array}\right]<0
\end{aligned}
$$

The time derivative of the Lyapunov function is definitely negative. Hence, the control system becomes asymptotically stable.

\section{Remedy for the Chattering Problem}

The SMC method designed earlier fast tracks the instantaneous active and reactive powers of the Vienna I rectifiers. However, fast switching may bring about unexpected chattering. The high-frequency components of the unexpected chattering may give rise to unmodeled high-frequency system transients and lead to unforeseen instability. The discontinuous part of the controller is smoothed out by utilizing a boundary layer around the sliding surface to eliminate the problem. A continuous switching function around the sliding surface neighborhood is obtained as follows:

$$
\operatorname{sign}\left(\mathrm{S}_{g}\right)= \begin{cases}1, & \text { if } \mathrm{S}_{g}>\lambda_{g} \\ \frac{S_{g}}{\lambda_{g}}, & \text { if }\left|\mathrm{S}_{g}\right|<\lambda_{g} \\ -1, & \text { if } \mathrm{S}_{g}<-\lambda_{g}\end{cases}
$$

where $\lambda_{g}$ is the width of the boundary layer, which is greater than zero (i.e., $g=1,2$ ).

The Vienna rectifier output voltage reference produced by each switching state is represented by the stationary voltage vectors in space by utilizing Eqs. (25) and (27). The collection of these stationary voltage vectors is directly transferred to the SVM module to generate the required switching voltage vectors and their respective duration times [27], [28].

\section{NEUTRAL-POINT VOLTAGE BALANCE STRATEGY BASED ON SIMPLIFIED SVM}

This paper proposes a new simplified SVM method for the Vienna I rectifier based on the simplification of the space vector diagram of a three-level converter into that of a two-level converter. All the remaining procedures necessary for the three-level SVM are performed similar to those of a conventional two-level inverter. Moreover, the execution 
TABLE II

Sector Definition by Voltage Vector and Transformation of Reference Voltage Vector

\begin{tabular}{|c|c|c|c|c|}
\hline \multirow{2}{*}{\multicolumn{2}{|c|}{$\frac{\text { Conditions }}{\left(v_{\alpha}>0 \& \& v_{\beta}>0 \& \& v_{g}>0\right) \|\left(v_{\alpha}>0 \& \& v_{\beta}<0 \& \& v_{h}>0\right)}$}} & \multirow{2}{*}{$\frac{\text { Sector }}{\mathrm{I}}$} & \multirow{2}{*}{$\begin{array}{c}\text { Equivalent } \\
\text { voltage reference } \\
v_{r e f}^{*}=v_{r e f}-v_{01}\end{array}$} & \multirow{2}{*}{$\begin{array}{c}\text { Equivalent } \alpha \beta \text { plane } \\
v_{\alpha}^{*}=v_{\alpha}-V_{d c} / 3, v_{\beta}^{*}=v_{\beta}\end{array}$} \\
\hline & & & & \\
\hline & $v_{\alpha}>0 \& \& v_{\beta}>0 \& \& v_{g}<0$ & II & $v_{r e f}^{*}=v_{r e f}-v_{02}$ & $v_{\alpha}^{*}=v_{\alpha}-V_{d c} / 6, v_{\beta}^{*}=v_{\beta}-\sqrt{3} V_{d c} / 6$ \\
\hline & $v_{\alpha}<0 \& \& v_{\beta}>0 \& \& v_{h}>0$ & III & $v_{r e f}^{*}=v_{r e f}-v_{03}$ & $v_{\alpha}^{*}=v_{\alpha}+V_{d c} / 6, v_{\beta}^{*}=v_{\beta}-\sqrt{3} V_{d c} / 6$ \\
\hline$\left(v_{\alpha}<0 \& \&\right.$ & $\left.>0 \& \& v_{h}<0\right) \|\left(v_{\alpha}<0 \& \& v_{\beta}<0 \& \& v_{g}<0\right)$ & IV & $v_{r e f}^{*}=v_{r e f}-v_{04}$ & $v_{\alpha}^{*}=v_{\alpha}+V_{d c} / 3, v_{\beta}^{*}=v_{\beta}$ \\
\hline & $v_{\alpha}<0 \& \& v_{\beta}<0 \& \& v_{g}>0$ & V & $v_{r e f}^{*}=v_{r e f}-v_{05}$ & $v_{\alpha}^{*}=v_{\alpha}+V_{d c} / 6, v_{\beta}^{*}=v_{\beta}+\sqrt{3} V_{d c} / 6$ \\
\hline & $v_{\alpha}>0 \& \& v_{\beta}<0 \& \& v_{h}<0$ & VI & $v_{r e f}^{*}=v_{r e f}-v_{06}$ & $v_{\alpha}^{*}=v_{\alpha}-V_{d c} / 6, v_{\beta}^{*}=v_{\beta}+\sqrt{3} V_{d c} / 6$ \\
\hline Remark & \multicolumn{4}{|l|}{$v_{g}=v_{\alpha}-\sqrt{3} v_{\beta}, v_{h}=v_{\alpha}+\sqrt{3} v_{\beta}$} \\
\hline
\end{tabular}

time is greatly reduced. The DC-link neutral-point voltage balance control algorithms are more easily implemented. Numerous PWM strategies have been proposed to solve the neutral-point voltage unbalance problem. Many of these techniques still use the complicated dwelling time calculation and the switching sequence selection method [12], [14], [16]. The neutral-point voltage control algorithm is easily implemented, and the dwelling time calculation and the switching sequence selection are easily conducted similar to that of a conventional two-level rectifier when the new PWM strategy is used.

Table I presents the currents that flow into the neutral point of the DC-bus capacitor bank and the $v_{N O}$ values. The space vector representation of the 25 electrical states in the $\alpha-\beta$ plane is illustrated in Fig. 2. The space vector diagram of the three-level rectifier is composed of six small hexagons, which are conventional two-level rectifiers (Fig. 5). Two steps have to be taken to simplify into the space vector module of a two-level rectifier. First, one hexagon has to be selected among the six hexagons from the location of a given reference voltage. Second, the original reference voltage vector has to be subtracted by the amount of the center voltage vector of the selected hexagon [12].

The origin of a reference voltage vector is changed to the center voltage vector of the selected hexagon once the sector is determined. This change is performed by subtracting the center vector of the selected hexagon from the original reference vector. Table II summarizes these processes. The reference voltage vector is then redefined in the new small hexagon. Moreover, the dwelling times are calculated in the same method as that of the conventional two-level SVM scheme. Take section $-30^{\circ} \sim 30^{\circ}$ as an example [Fig. 5(b)]. The equivalent reference vector is sampled at a regular interval of time $T_{s}$. The sampled reference vector is approximated by time-averaging the nearest three vectors (i.e., $v_{x}, v_{y}$, and $\left.v_{z}\right) . T_{x}, T_{y}$, and $T_{z}$ are the dwell times of the nearest three vectors. The expression is then given as follows according to the volt-second balance principle:
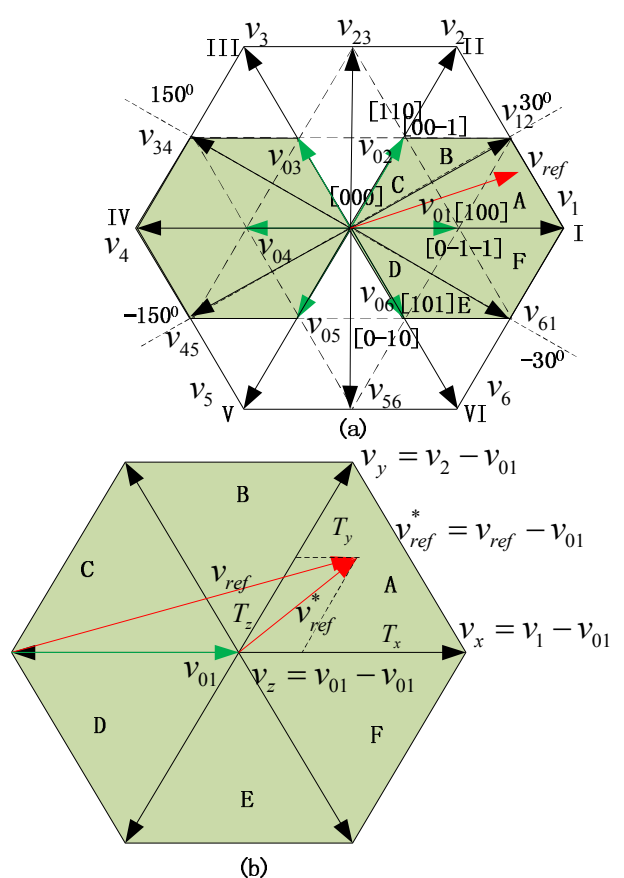

Fig. 5. (a) Simplification of a three-level space vector diagram; and (b) time division calculation.

$$
\left\{\begin{array}{c}
T_{x} v_{x}+T_{y} v_{y}+T_{z} v_{z}=T_{s} v_{r e f}^{*} \\
T_{x}+T_{y}+T_{z}=T_{s}
\end{array}\right.
$$

The redundant vector $v_{z}$ is used to charge or discharge the DC-link midpoint given the existent neutral conduction path of the Vienna rectifier. Its vector realizations are represented by $v_{z}^{-}$and $v_{z}^{+}$. Subsequently, Eq. (28) is rewritten as follows:

$$
\left\{\begin{array}{l}
T_{x} v_{x}+T_{y} v_{y}+\frac{T_{z}(1+f) v_{z}^{-}}{2}+\frac{T_{z}(1-f) v_{z}^{+}}{2}=T_{s} v_{r e f}^{*} \\
T_{x}+T_{y}+\frac{T_{z}(1+f)}{2}+\frac{T_{z}(1-f)}{2}=T_{s}
\end{array}\right.
$$

where $f$ is a time factor used to rearrange the time distribution of the redundant voltage vectors. The neutral point voltage in this case is controlled by adjusting the time distribution of the redundant voltage vectors in response to the voltage error and 
TABLE III

Basic Equivalent Vector and Respective Time of Section I

\begin{tabular}{|c|c|c|c|c|c|c|c|c|c|}
\hline \multirow{2}{*}{ Sector } & \multicolumn{5}{|c|}{ Equivalent vector } & \multicolumn{6}{c|}{ Equivalent time } \\
\cline { 2 - 10 } & $v_{x}$ & $v_{y}$ & $v_{z}^{+}$ & $v_{z}^{-}$ & $T_{x}$ & $T_{y}$ & $T_{z}$ & $T_{z}^{+}$ & $T_{z}^{-}$ \\
\hline $\mathrm{A}$ & $v_{1}-v_{01}$ & $v_{12}-v_{01}$ & $v_{01}^{+}-v_{01}^{+}$ & $v_{01}^{-}-v_{01}^{-}$ & $Z$ & $X$ & $T_{s}-X-Z$ & $T_{z}(1-f) / 2$ & $T_{z}(1+f) / 2$ \\
\hline $\mathrm{B}$ & $v_{12}-v_{01}$ & $v_{02}-v_{01}$ & $v_{01}^{+}-v_{01}^{+}$ & $v_{01}^{-}-v_{01}^{-}$ & $Y$ & $-Z$ & $T_{s}-Y+Z$ & $T_{z}(1-f) / 2$ & $T_{z}(1+f) / 2$ \\
\hline $\mathrm{C}$ & $v_{02}-v_{01}$ & $v_{0}-v_{01}$ & $v_{01}^{+}-v_{01}^{+}$ & $v_{01}^{-}-v_{01}^{-}$ & $X$ & $-Y$ & $T_{s}-X+Y$ & $T_{z}(1-f) / 2$ & $T_{z}(1+f) / 2$ \\
\hline $\mathrm{D}$ & $v_{0}-v_{01}$ & $v_{06}-v_{01}$ & $v_{01}^{+}-v_{01}^{+}$ & $v_{01}^{-}-v_{01}^{-}$ & $-Z$ & $-X$ & $T_{s}+X+Z$ & $T_{z}(1-f) / 2$ & $T_{z}(1+f) / 2$ \\
\hline $\mathrm{E}$ & $v_{06}-v_{01}$ & $v_{61}-v_{01}$ & $v_{01}^{+}-v_{01}^{+}$ & $v_{01}^{-}-v_{01}^{-}$ & $-Y$ & $Z$ & $T_{s}+Y-Z$ & $T_{z}(1-f) / 2$ & $T_{z}(1+f) / 2$ \\
\hline $\mathrm{F}$ & $v_{61}-v_{01}$ & $v_{1}-v_{01}$ & $v_{01}^{+}-v_{01}^{+}$ & $v_{01}^{-}-v_{01}^{-}$ & $-X$ & $Y$ & $T_{s}+X-Y$ & $T_{z}(1-f) / 2$ & $T_{z}(1+f) / 2$ \\
\hline
\end{tabular}

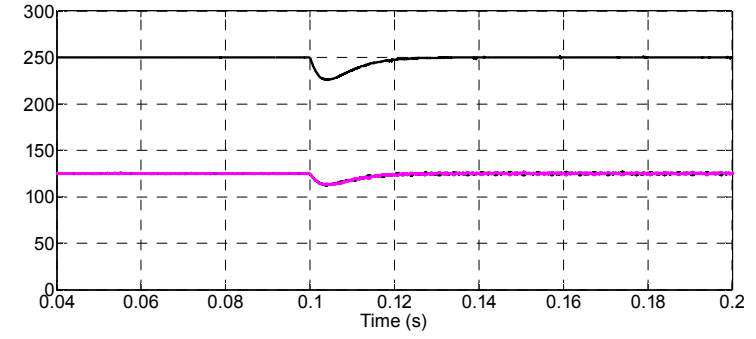

(a)

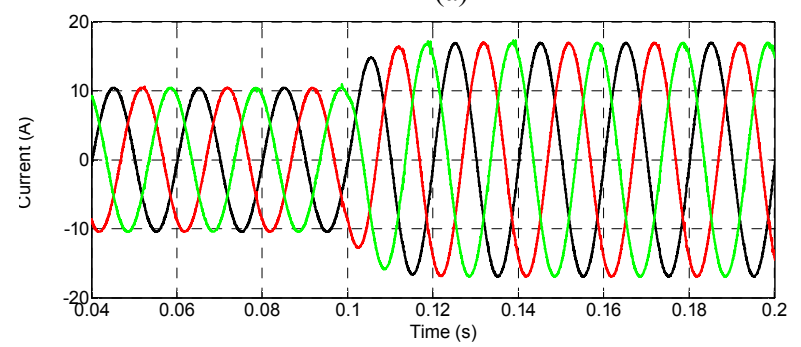

(c)

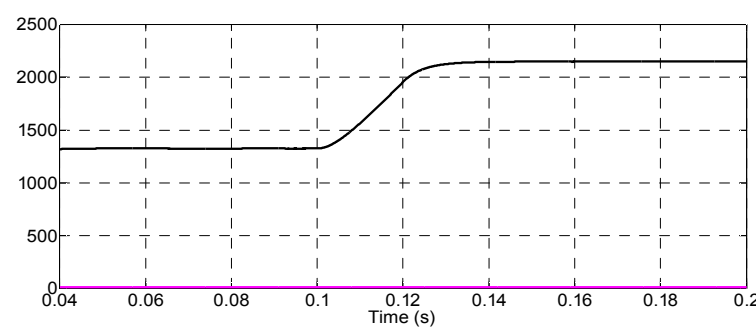

(b)

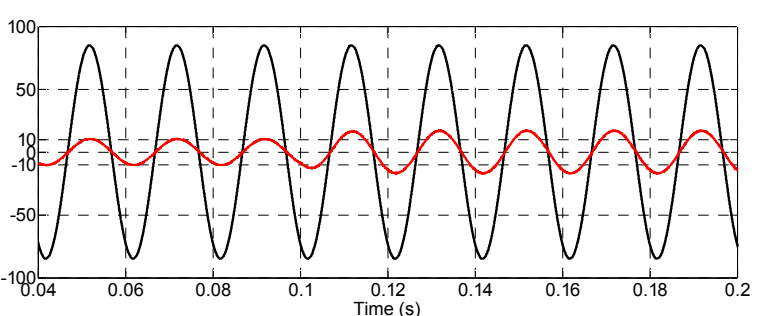

(d)

Fig. 6. Simulation results of the load change with the load resistance steps from $50 \Omega$ to $28 \Omega$. (a) Full DC-link voltage ( $v_{d c}$ ) and two capacitor voltages $\left(v_{c p}\right.$ and $\left.v_{c n}\right)$. (b) Active power $(P)$ and reactive power $(Q)$. (c) Rectifier phase currents $\left(i_{a}, i_{b}\right.$, and $\left.i_{c}\right)$. (d) waveforms are the source voltage $\left(u_{b}\right)$ and phase b current $\left(i_{b}\right)$.

the current conditions [21]. The relationship between the currents that inject the neutral point and the neutral point voltage has been introduced in detail in Section II. Time factor $f$ is generated using the PI regulator by detecting the $\Delta V_{d c}\left(v_{c p}-v_{c n}\right)$. Hence, the neutral point voltage balance is effectively managed. The conduction time of the vectors is then finally determined as follows:

$$
\left\{\begin{array}{l}
T_{x}=\left(3 v_{\alpha}^{*} / V_{d c}-\sqrt{3} v_{\beta}^{*} / V_{d c}\right) T_{s} \\
T_{y}=\left(2 \sqrt{3} v_{\beta}^{*} / V_{d c}\right) T_{s} \\
T_{z}=T_{s}-T_{x}-T_{y}
\end{array}\right.
$$

The dwelling times are calculated similar to that of the conventional two-level SVM method if the reference voltage vector is redefined as explained in the previous section. The conduction time of the other five regions is summarized in Table III based on the preceding analysis.

$X, Y$, and $Z$ are respectively defined as follows:

$$
\left\{\begin{array}{l}
X=\left(\sqrt{3} v_{\beta}^{*} / V_{d c}\right) T_{s} \\
Y=\left(3 v_{\alpha}^{*} / 2 V_{d c}+\sqrt{3} v_{\beta}^{*} / 2 V_{d c}\right) T_{s} \\
Z=\left(3 v_{\alpha}^{*} / 2 V_{d c}-\sqrt{3} v_{\beta}^{*} / 2 V_{d c}\right) T_{s}
\end{array}\right.
$$

\section{SIMULATION AND EXPERIMENTAL RESULTS}

A detailed simulation is built in this section to verify the proposed control strategy on a MATLAB/SIMULINK platform. The circuit parameters are listed in Table IV used in the small-scale simulation model.

Accordingly, Fig. 6 shows the transient response for a load step-up case to verify the dynamic performance. The load resistance steps in the case range from $50 \Omega$ to $28 \Omega$. The simulation results indicate that the proposed control approach is stable under the load-step transient condition. The steady-state waveforms of the Vienna I rectifiers, steady-state current, and differential voltage are shown in Fig. 7. Both the DC-link voltages and the AC input currents are 


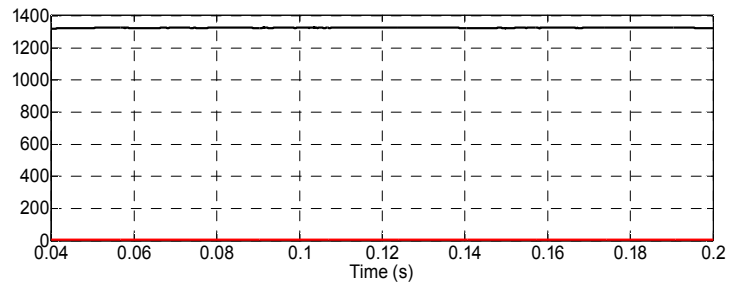

(a)

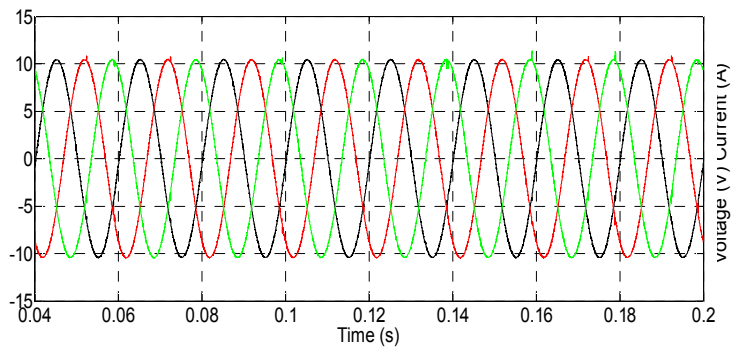

(c)

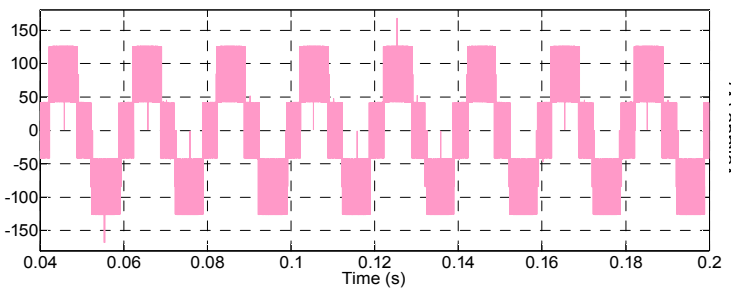

(e)

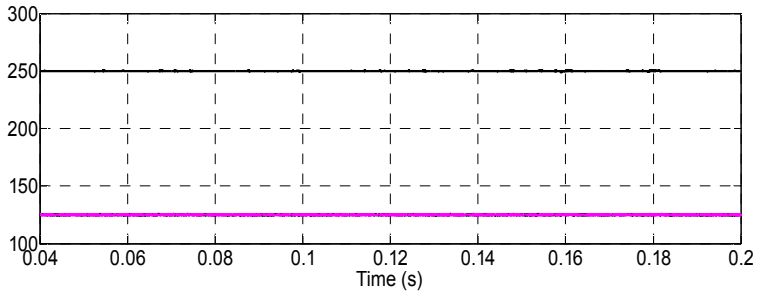

(b)

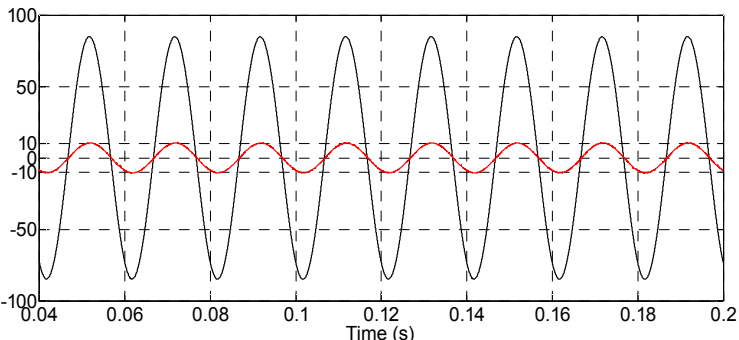

(d)

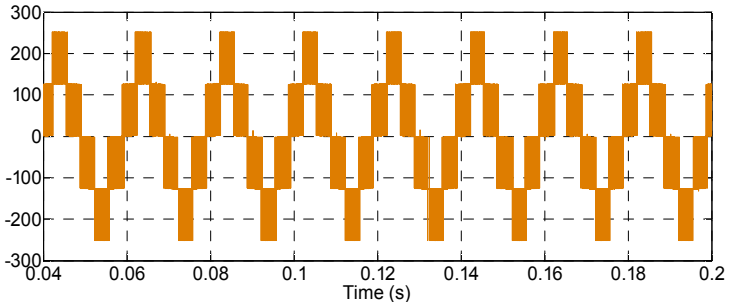

(f)

Fig. 7. Simulation results of the steady state operating in $1.32 \mathrm{~kW}$ load with the SMC-based DPC. (a) Active power $(P)$ and reactive power $(Q)$; (b) full DC-link voltage $\left(v_{d c}\right)$ and two capacitor voltages $\left(v_{c p}, v_{c n}\right)$; (c) rectifier phase currents $\left(i_{a}, i_{b}\right.$, and $\left.i_{c}\right)$; $(\mathrm{d})$ waveforms are the source voltage $\left(u_{b}\right)$ and phase b current $\left(i_{b}\right)$; (e) rectifier pole to the main point voltage ( $\left.v_{b o}\right)$; and (f) rectifier pole-to-pole voltage $\left(v_{a b}\right)$.

TABLE IV

PARAMETERS USED IN THE SIMULATION

\begin{tabular}{c|l}
\hline RMS source voltage & $60 \mathrm{~V}$ \\
\hline Source frequency & $50 \mathrm{~Hz}$ \\
\hline Input inductance $\mathrm{L}$ & $4 \mathrm{mH}$ \\
\hline Switching frequency & $25 \mathrm{kHz}$ \\
\hline DC link voltage & $250 \mathrm{~V}$ \\
\hline DC link capacitor & $470 \mu \mathrm{F}$ \\
\hline Load resistance & $50 \Omega$ \\
\hline Positive gains (i.e., $K_{P}$ and $K_{Q}$ ) & 5500 and 3500 \\
\hline Control gains (i.e., $k_{1}$ and $k_{2}$ ) & 4000 \\
\hline Layer width (i.e., $\lambda_{1}$ and $\lambda_{2}$ ) & 150 and 200 \\
\hline
\end{tabular}

well controlled. Hence, the power factor is close to unity one. Furthermore, the neutral point voltage balance has been effectively controlled.

A comparative simulation study of the DPC based on the PI controller is conducted using the same circuit parameters to verify the performance of the proposed DPC based on the SMC approach. The transient response for a load step-up is

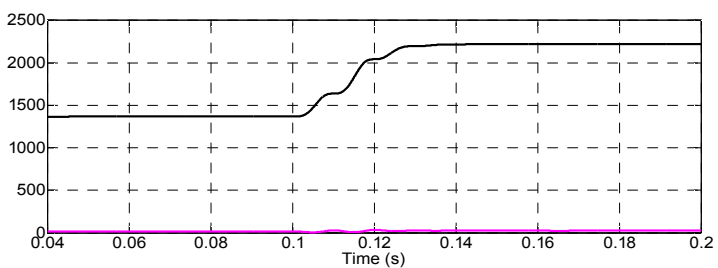

(a)

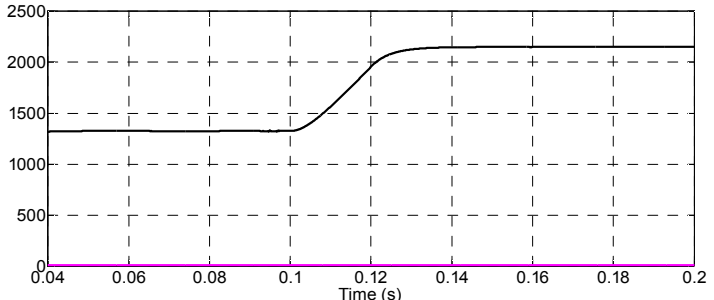

(b)

Fig. 8. Simulation results of the active and the reactive power steps using two methods: (a) DPC based on the PI method and (b) DPC based on the SMC approach.

used to analyze the system response during the active and the reactive power steps in the two systems. The active power increases from $1.2 \mathrm{~kW}$ to $2.2 \mathrm{~kW}$ at $0.035 \mathrm{~s}$ [Fig. 8(a)]. The reactive power definitely has a small ripple. The active power 


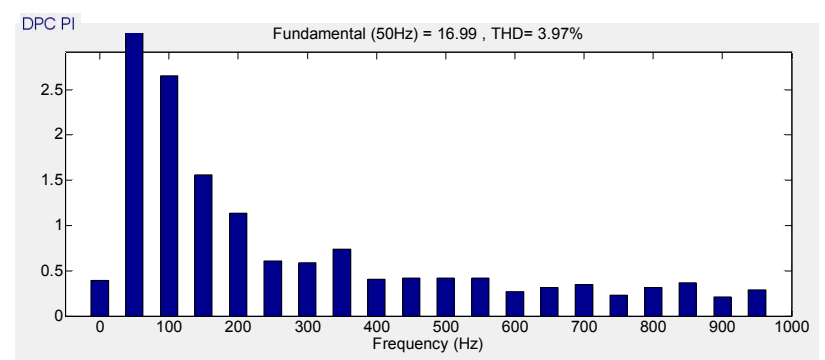

(a)

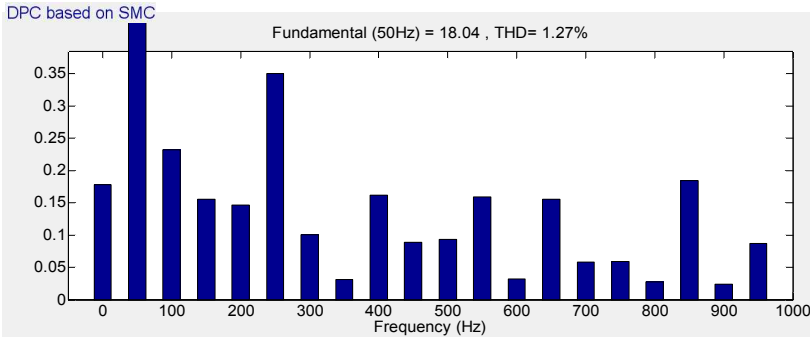

(b)

Fig. 9. Simulation results of the current harmonic spectra and the total harmonic distortions. (a) DPC based on the PI method. (b) DPC based on the SMC approach.

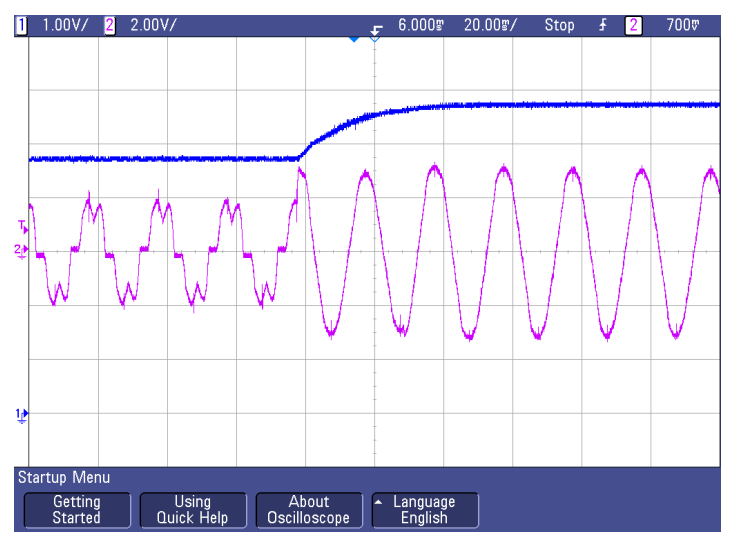

(a)

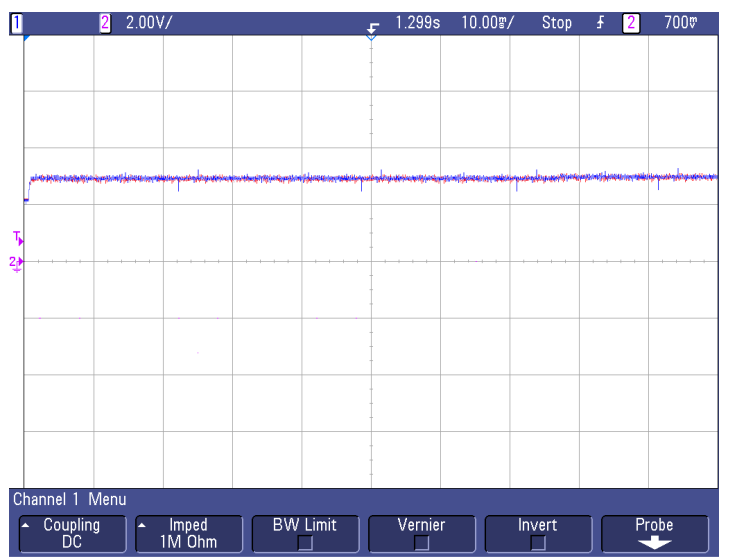

(c)

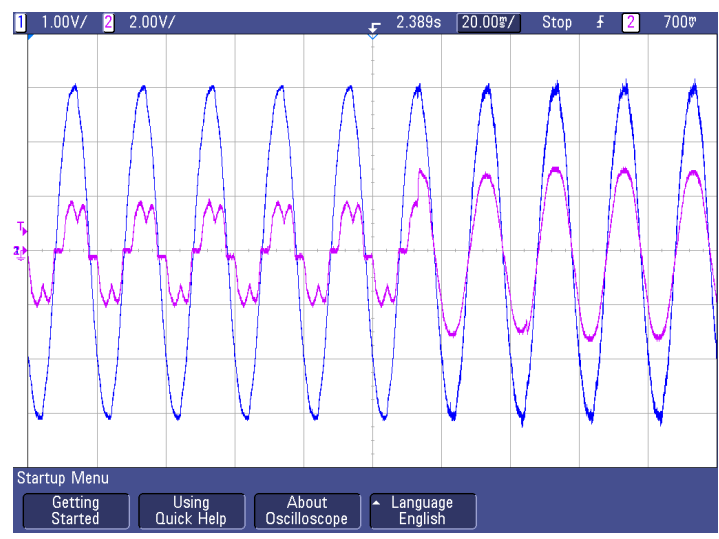

(b)

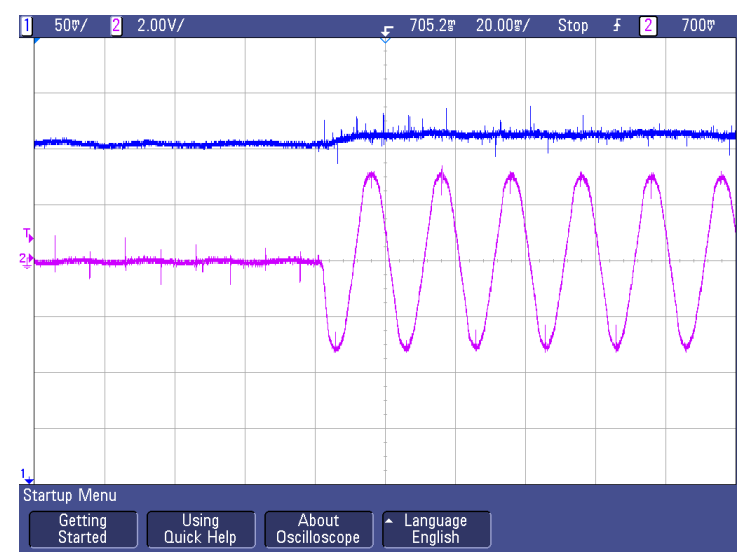

(d)

Fig. 10. Experimental results of startup and steady states. (a) Full dc voltage $v_{d c}$ and ac current $i_{b}$. (b) Source voltage $u_{b}$ and phase $\mathrm{b}$ current $i_{b}$. (c) Two capacitors voltage $v_{c p}, v_{c n}$, (d) full dc voltage $v_{d c}$ and ac current $i_{b}$ with the load resistance steps from disconnected state to normally steady state.

changes in the same condition at $0.025 \mathrm{~s}$ [Fig. 8(b)]. Furthermore, the reactive power is still zero and has no ripple. Accordingly, Fig. 9 provides the current harmonic spectra and the total harmonic distortions (THDs) for each control strategy to further compare the performances of the two control methods. The active and the reactive power waveforms are much smoother. In addition, they contain fewer ripples than the DPC based on the PI control method.

An experimental prototype is built at laboratory scale to further illustrate and validate the proposed method. The input voltage is $110 \mathrm{Vrms} / 50 \mathrm{~Hz}$. The inductors are $4 \mathrm{mH}$, and the switch frequency is $20 \mathrm{kHz}$. The two DC-link capacitors connected in series at the DC side are $760 \mu \mathrm{F}$, and the load resistor is $50 \Omega$. Moreover, the DC reference voltage is $300 \mathrm{~V}$. The differential waveforms are presented in Fig. 10. The transient waveforms of the DC voltage and the AC current are shown in Fig. 10(a). At the same time, the waveforms are used to depict steady state. The relations between the AC current and the AC source voltage are further illustrated in Fig. 10(b). The sinusoidal and the symmetrical currents are 


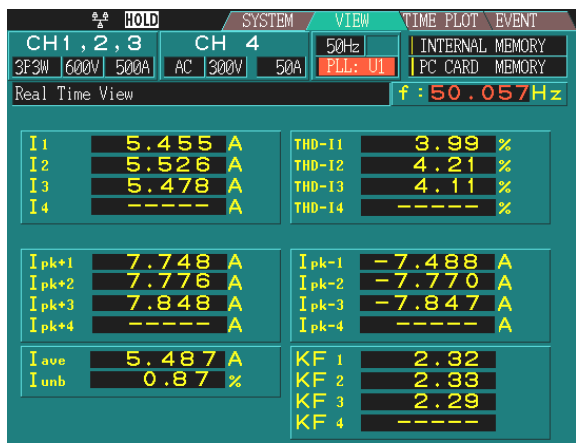

(a)

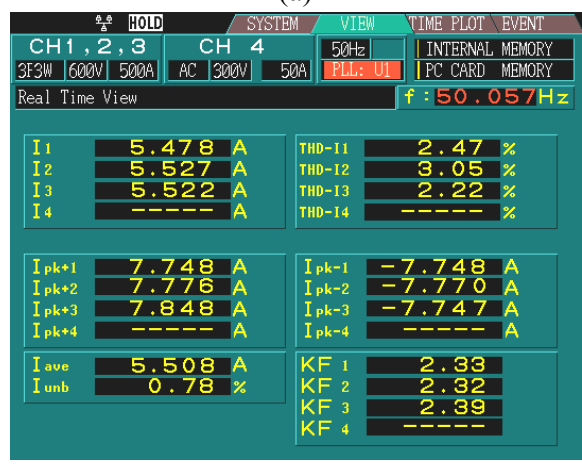

(b)

Fig. 11. Experimental results of the three-phase currents and the three-phase current harmonic distortions. (a) DPC based on the PI method. (b) DPC based on the SMC approach.

obtained with the same phase angle and source voltages when the rectifier changes from the diode rectification mode to the active control mode. The neutral-point voltage balance of the DC-link capacitors is well regulated by the method based on the simplified SVM [Fig. 10(c)]. The transient response for a load step-up case, in which the load resistance steps from the disconnected state to the normally steady state, is presented in Fig. 10(d).

The three-phase current values and the three-phase THDs for each control strategy are illustrated in Fig. 11. The THDs based on the SMC are lower than those on DPC based on the PI control method.

\section{CONCLUSION}

This paper establishes a new power model and a high-frequency model of the Vienna I rectifier based on the two models. Furthermore, a new control approach (i.e., DPC based on the SMC) is proposed. The required control voltage of the rectifier is directly calculated by utilizing the non-linear SMC scheme with no cross coupling or rotating transformation. Moreover, the simplified SVM method is conducted similar to a conventional two-level converter, and the execution time is greatly reduced. Therefore, the proposed scheme significantly reduces computation efforts, and a high-quality line current waveform is obtained. The simplified SVM method indicates that the DC-link neutral-point voltage balance of the Vienna rectifier is more easily implemented by managing the time factor.
Compared with the DPC based on the PI controllers under the same conditions, the proposed approach exhibits better performance with fast response time and no active and reactive power ripples. The proposed control scheme and model are verified through simulation and experimental analysis. The results show that the SMC-based DPC is an effective method for use in the Vienna I rectifier system.

\section{REFERENCES}

[1] J. W. Kolar and U. Drofenik, "A new switching loss reduced discontinuous PWM scheme for a unidirectional three-phase/switch/level boost-type PWM (VIENNA) rectifier," in Telecommunication Energy Conference, 1999. INTELEC '99. The 21st International, pp.490-499, 1999.

[2] J. W. Kolar, U. Drofenik, and F. C. Zach, "Current handling capability of the neutral point of a three-phase/switch/level boost-type PWM (VIENNA) rectifier,"in Power Electronics Specialists Conference, 1996. PESC '96 Record., 27th Annual IEEE, pp. 1329-1336, 1996.

[3] J. Alahuhtala and H. Tuusa, "Space vector modulation method for unidirectional four-wire three-phase/level/switch (Vienna) rectifier," in Power Electronics, 2007. ICPE '07. 7th Internatonal Conference on, pp. 742-748, 2007.

[4] T. Viitanen and H. Tuusa, "Space vector modulation and control of a unidirectional three-phase/level/switch VIENNA I rectifier with LCL-type AC filter," in Power Electronics Specialist Conference, 2003. PESC '03. 2003 IEEE 34th Annual, Vol. 3, pp. 1063-1068, 2003.

[5] L. Rixin, W. Fei, R. Burgos, D. Boroyevich, J. Dong, and Di Zhang, "Average modeling and control design for VIENNA-type rectifiers considering the DC-link voltage balance," IEEE Trans. Power Electron., Vol. 24, No. 11, pp. 2509-2522, Nov. 2009.

[6] N. Backman and R. Rojas, "Modern circuit topology enables compact power factor corrected three-phase rectifier module," in Telecommunications Energy Conference, 2002. INTELEC. 24th Annual International, pp. 107-114, 2002.

[7] R. Greul, U. Drofenik, and J. W. Kolar, "Analysis and comparative evaluation of a three-phase three-level unity power factor y-rectifier," in Telecommunications Energy Conference, 2003. INTELEC '03. The 25th International, pp. 421-428, 2003.

[8] J. W. Kolar and F. C. Zach, "A novel three-phase utility interface minimizing line current harmonics of high-power telecommunications rectifier modules," IEEE Trans. Ind. Electron., Vol. 44, No. 4, pp. 456-467, Aug. 1997.

[9] B. Wang, G. Venkataramanan, and A. Bendre, "Unity power factor control for three-phase three-level rectifiers without current sensors," IEEE Trans. Ind. Appl., Vol. 43, No. 5, pp. 1341-1348, Sep./Oct. 2007.

[10] R. Greul, S. D. Round, and J. W. Kolar, "Analysis and control of a three-phase, unity power factor Y-rectifier," IEEE Trans. Power Electron., Vol. 22, No. 5, pp. 1900-1911, Sep. 2007.

[11] Q. Chongming and K. M. Smedley, "Three-phase unity-power-factor star-connected switch (VIENNA) rectifier with unified constant-frequency integration control," IEEE Trans. Power Electron., Vol. 18, No. 4, pp. 952-957, Jul. 2003.

[12] R. Burgos, L. Rixin, P. Yunqing, W. Fei, D. Boroyevich, and J. Pou, "Space vector modulator for vienna-type rectifiersbased on the equivalence between two- and three-level converters: A carrier-based implementation," IEEE Trans. Power Electron., Vol. 23, No. 4, pp. 1888-1898, Jul. 2008. 
[13] X. Zhuang and M. Faz Rahman, "Direct torque and flux regulation of an IPM synchronous motor drive using variable structure control approach," IEEE Trans. Power Electron., Vol. 22, No. 6, pp. 2487-2498, Nov. 2007.

[14] J. Eloy-Garcia, J. Eloy-Garcia, and R. Alves, "DSP-based direct power control of a VSC with voltage angle estimation," in Transmission \& Distribution Conference and Exposition: Latin America, 2006. TDC '06. IEEE/PES. pp. 1-5, 2006.

[15] C. Gong, J. Wan, K. Li, S. Huang, and L. Shi, "Direct capacitor power control of dual PWM converter based on sliding mode variable structure, "in Innovative Smart Grid Technologies-Asia(ISGT Asia), 2012 IEEE. pp. 1-5, 2012.

[16] H. Chen, S. Zhang, and L. Liu, "Control three-phase star-connected switch three-level rectifier considering alternative performance indices, "in Intelligent Control and Automation (WCICA), 2012 10th World Congress on, pp. 2506-2511, 2012.

[17] W. Chenchen and L. Yongdong, "Analysis and calculation of zero-sequence voltage considering neutral-point potential balancing in three-level NPC converters," IEEE Trans. Ind. Electron., Vol. 57, No. 7, pp. 2262-2271, Jul. 2010.

[18] E. Pouresmaeil, D. Montesinos-Miracle, and O. Gomis-Bellmunt, "Control scheme of three-level NPC inverter for integration of renewable energy resources into AC grid," IEEE Syst. J., Vol. 6, No. 2, pp. 242-253, Jun. 2012.

[19] P. N. Tekwani, R. S. Kanchan, and K. Gopakumar, "Current-error space-vector-based hysteresis PWM controller for three-level voltage source inverter fed drives," Electric Power Applications, IEE Proceedings, Vol. 152, No. 5, pp. 1283-1295, 2005.

[20] C. Xia, X. Gu, T. Shi, and Y. Yan, "Neutral-point potential balancing of three-level inverters in direct-driven wind energy conversion system," IEEE Trans. Energy Convers., Vol. 26, No. 1, pp. 18-29, Mar.2011.

[21] J. Pou, D. Boroyevich, and R. Pindado, "New feedforward space-vector PWM method to obtain balanced AC output voltages in a three-level neutral-point-clamped converter," IEEE Trans. Ind. Electron.,, Vol. 49, No. 5, pp. 1026-1034, Oct. 2002.

[22] U. Choi, J. Lee, and K. Lee, "New modulation strategy to balance the neutral-point voltage for three-level neutral-clamped inverter systems," IEEE Trans. Energy Convers., Vol. 29, No.1, pp. 91-100, Mar. 2014.

[23] Y. Zhezhi, Y. Lingzhi, P. Hanmei, F. Xi, and D. Dong, "Study of simplified SVPWM algorithm based on three-level inverter," in Power Electronics and Motion Control Conference, 2009. IPEMC '09. IEEE 6th International. pp. 876-881, 2009.

[24] B. B. F. Bouaziz, "Direct power control of grid-connected converters using sliding mode controller," in Electrical Engineering and Software Applications (ICEESA), 2013 International Conference on. pp. 1-6, 2013.

[25] W. Chen, W. Chen, Y. Zou, Y. Zou, L. Xu, and L. Xu, "Direct power control for Neutral-point-clamped three-level PWM rectifier," in Industrial Technology 2008. ICIT 2008. IEEE International Conference on, pp. 1-6, 2008.

[26] T. Lu, Z. Zhao, L. Yuan, F. He, and Y. Zhang, "Uncoupled direct power control based on improved sector selection algorithm for three-level PWM rectifier," in Energy Conversion Congress and Exposition (ECCE), 2013 IEEE, pp. 1364-1370, 2013.

[27] H. Jingjing, Z. Aimin, C. Xiaoju, Z. Hang, and W. Jianhua, "A novel direct power control strategy of double hysteresis and multiple switching tables for rectifiers," in Advanced Power System Automation and Protection (APAP), 2011 International Conference on, pp. 36-41, 2011.
[28] J. Hu, H. Nian, B. Hu, Y. He, and Z. Q. Zhu, "Direct active and reactive power regulation of DFIG using sliding-mode control approach," IEEE Trans. Energy Convers., Vol. 25, No. 4, pp. 1028-1039, Dec. 2010.

[29] R. K. R. Aghatehrani, "Sliding mode control approach for voltage regulation in microgrids with DFIG based wind generations," in Power and Energy Society General Meeting, 2011 IEEE, pp. 1-8, 2011.

[30] G. Abad, M. A. Rodriguez, and J. Poza, "Three-level NPC converter-based predictive direct power control of the doubly fed induction machine at low constant switching frequency," IEEE Trans. Ind. Electron., Vol. 55, No. 12, pp. 4417-4429, Dec. 2008.

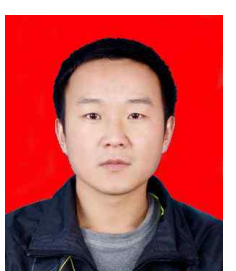

Hui Ma was born in Kaifeng, Henan Province, China in 1985. He received the M.S. degree in Electrical Engineering and Automation from Chang Chun University of Technology, Jilin, China in 2013. He is currently working toward his Ph.D. in Electrical Engineering at the South China University of Technology, Guangzhou, China. His research interests include high-power density rectifiers, multilevel converters, and control strategies.

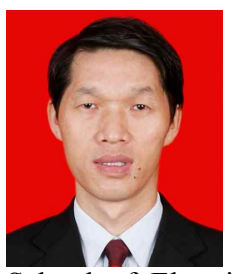

Yunxiang Xie was born in Shaoyang, Hunan Province, China in 1965. He received his B.S., M.S., and Ph.D. degrees in Electrical Engineering from Xian Jiaotong University, Xian, China in 1985, 1988, and 1991, respectively. $\mathrm{He}$ was a postdoctoral researcher from 1991 to 1994 and an associate professor from 1994 to 1999 in the School of Electrical Power, South China University of Tech, Guangzhou, China. He has been a professor of the same department at the South China University of Tech since 1999. He is a senior member of the China Electrotechnique Society and the director of the Electrical Energy-saving Special Committee of the China Electrotechnical Society. While teaching in the Chinese Society of Mechanical Education and Chinese Power Industry Education Association of Electrical Engineering and Automation Committee, he authored or coauthored more than 170 published technical papers. His research areas include power electronics and control, including high-power density rectifiers, multilevel converters, active filter, and distributed power quality and control strategies.

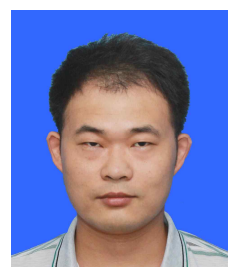

Biaoguang Sun was born in Xinxiang, Henan Province, China, in 1984. He received his B.S. and M.S. degrees in Automation from Henan Polytechnic University, Luoyang, China in 2008 and 2011, respectively. He is currently working toward a Ph.D. in Electrical Engineering at the South China University of Technology, Guangzhou, China. His research interests include high-power density rectifiers, active filter, and distributed power quality.

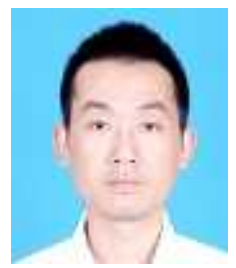

Lingjun Mo was born in Huaihua, Hunan Province, China, in 1982. He received his B.S degree in Electronic and Information Engineering from Ji Shou University, Jishou, China, in 2004. He is currently working toward his M.S. degree in Electrical Engineering at the South China University of Technology, Guangzhou, China. His research interests include high-power density rectifiers, multilevel converters, and distributed power generation systems. 